\title{
FENOMENOLOGIA DA QUALIDADE DE VIDA DE MÃES DE CRIANÇAS AUTISTAS
}

\author{
Phenomenology of the Quality of Life of Autistic Children \\ Fenomenología de la calidad de vida de las madres de los niños Autistas
}

\begin{abstract}
Resumo: A qualidade de vida (QV) das mães de crianças com transtorno do espectro autista (TEA) está relacionada com características sintomáticas e idiopáticas da condição existencial da criança e é determinada pelas compreensões subjetivas atribuídas de acordo com a experiência individual. O objetivo primário deste artigo é descrever e compreender as construções subjetivas sobre a QV autorreferenciada de mães de crianças com TEA. Trata-se de um estudo empírico, qualitativo e fundamentado na leitura da psicopatologia fenomenológica. Participaram 10 mães de crianças com TEA, usuárias dos serviços públicos de saúde de Goiânia. Utilizou-se como instrumentos: questionário de dados sociodemográficos e clínicos e roteiro de entrevista semiestruturada sobre QV. As entrevistas foram submetidas à construção de categorias temáticas, segundo a metodologia de Giorgi (1985), e posteriormente foram correlacionadas com as categorias existenciais de Augras (2004). Observou-se que ainda que se busque padrão para compreender a QV, cada mãe dispõe de fatores subjetivos que refletem sua forma de experienciar a condição de ser mãe de uma criança com necessidades especiais. Conclui-se que cabe a ciência, ao buscar compreender a qualidade de vida de pessoas com características similares, considerar a relevância dos aspectos subjetivos e o significado que cada mãe constrói de sua própria realidade.
\end{abstract}

Palavras-chaves: Qualidade de Vida; Mãe; Transtorno do Espectro Autista; Psicopatologia. Fenomenológica.

\begin{abstract}
The quality of life (QOL) of mothers of children with autism spectrum disorder (ASD) is related to the symptomatic and idiopathic characteristics of the existential condition of the child and is determined by the subjective understandings attributed according to the individual experience. The primary objective of this article is to describe and understand the subjective constructs about the self-referenced QOL of mothers of children with ASD. It is an empirical study, qualitative and based on a reading of phenomenological psychopathology. Participated 10 mothers of children with ASD, users of public health services in Goiânia. The following instruments were used: a sociodemographic and clinical data questionnaire and a semistructured interview script about QOL. The interviews were submitted to the construction of thematic categories, according to the methodology of Giorgi (1985), and later were correlated with the existential categories of Augras (2004). It was observed that although a standard is sought to understand QOL, each mother has subjective factors that reflect in her way of experiencing the condition of being a mother of a child with special needs. It is concluded that it is the science, when seeking to understand the quality of life of people with similar characteristics, to consider the relevance of the subjective aspects and the meaning that each mother constructs of its own reality.
\end{abstract}

Keywords: Quality of Life; Mother; Autism Spectrum Disorder; Phenomenological Psychopathology.

Resumen: La calidad de vida (QV) de las madres de niños con trastorno del espectro autista (TEA) está relacionada con características sintomáticas e idiopáticas de la condición existencial del niño y está determinada por las comprensiones subjetivas atribuidas de acuerdo con la experiencia individual. El objetivo primario de este artículo es describir y comprender las construcciones subjetivas sobre la QV autorreferenciada de madres de niños con TEA. Se trata de un estudio empírico, cualitativo y fundamentado en la lectura de la psicopatología fenomenológica. Participaron 10 madres de niños con TEA, usuarias de los servicios públicos de salud de Goiânia. Se utilizó como instrumentos: cuestionario de datos sociodemográficos y clínicos y guión de entrevista semiestructurada sobre QV. Las entrevistas fueron sometidas a la construcción de categorías temáticas, según la metodología de Giorgi (1985), y posteriormente fueron correlacionadas con las categorías existenciales de Augras (2004). Se observó que aunque se busca patrón para comprender la CV, cada madre dispone de factores subjetivos que reflejan su forma de experimentar la condición de ser madre de un niño con necesidades especiales. Se concluye que cabe la ciencia, al buscar comprender la calidad de vida de personas con características similares, considerar la relevancia de los aspectos subjetivos y el significado que cada madre construye de su propia realidad.

Palabras claves: Calidad de Vida; Madre; Trastorno del Espectro Autista; Psicopatología Fenomenológica. 


\section{Introdução}

O Transtorno do Espectro Autista (TEA) segundo a Associação Americana de Psiquiatria (APA), por meio do Manual Diagnóstico e Estatístico de Transtornos Mentais, o DSM-5 (2014), é considerado um transtorno do neurodesenvolvimento, que abrange os termos descritos anteriormente como: Transtorno Desintegrativo, Transtorno Global do Desenvolvimento, Autismo e Síndrome de Asperger (DSM-5, 2014). Ainda alicerçado neste manual, o TEA é explicado como manifestações sintomáticas, até os três anos de idade, de déficits na comunicação e interação social e padrões restritos e repetitivos de comportamento, interesse e atividades.

Para além das compreensões sintomatológicas, de acordo com o Dicionário da Língua Portuguesa Aurélio, o termo "transtorno" significa uma perturbação e/ ou um desarranjo mental. Já a palavra "espectro" faz menção a obscuridade e fantasia de algo ameaçador; e, por fim, a palavra "autismo": representa um fenômeno patológico caracterizado pelo desligamento da realidade exterior e criação mental de um mundo autônomo (Ferreira, 2007).

Em interface às características sintomatológicas e a definição da nomenclatura, ainda que o TEA possua uma definição e um conjunto de sintomas para realização diagnóstica, não se tem uma causa etiológica e epidemiológica unificada definida para o transtorno, o que evidencia a necessidade de investigações idiopáticas para a sua compreensão (DMS-5, 2014).

Uma das abordagens capazes de repensar o TEA a partir das investigações idiopáticas é a Psicopatologia Fenomenológica, que se configura a partir de uma tentativa de reconsiderar os fundamentos da psiquiatria e também os conceitos gerais das patologias e dos aspectos gerais da vida, assim como de saúde e doença (Rovaletti, 2015). Para Petrelli (2017) o TEA deve ser compreendido em duas categorizações fenomenológicas do fenômeno, sendo elas: sintomática - déficit estruturais do funcionamento do sistema nervoso central; e idiopática - efeito da complexa síndrome do isolamento afetivo-social-contativo. Ainda na perspectiva deste autor, a abordagem Fenomenológica garante com relativa segurança a compreensão da complexidade do problema no circuito metodológico: corpo-mente-espírito. Como afirma Binswanger (1977) e Minkowski (1973), a psicologia é a ciência da mente e do espírito e a psicopatologia é um saber amplo que abrange dos dramas da vida aos mistérios da existência humana. Psicopatologia se define, para Moreira (2011), como patologia dos transtornos mentais, ou como o estudo das causas e natureza dos transtornos mentais. Ainda de acordo com a autora, a psicopatologia como disciplina nasceu na França no início do século XX, e após a publicação de Psicopatologia Geral de Karl Jasper, em 1913, a psicopatologia fenomenológica começou a se desenvolver. $\mathrm{O}$ estudo da psicopatologia numa perspectiva fenomenológica possibilita reflexões essenciais sobre aspectos da ontologia, permitindo intervenções mais precisas ligadas ao cotidiano do ser, que dialogam com a insegurança e provisoriedade da própria existência humana, apresenta Karwowski (2015).

Direcionando para a compreensão dos fenômenos psicopatológicos, Laplanche e Pontalis (1992) enfatizam entre diversas definições de transtorno, a incapacidade de adaptação social, a gravidade dos sintomas, a dificuldade de comunicação, a ausência de insight da condição mórbida vivida, a perda do contato com o real, o determinismo orgânico ou psicogenético e as alterações profundas do funcionamento do ego. Ainda nesta perspectiva, Antony (2012) descreve o autismo como um adoecer gerado pelo isolamento afetivo, que consequentemente afeta as introjeções daquilo que é ensinado, levando a criança a bloquear a comunicação do organismo com o ambiente, diminuindo sua capacidade de estabelecer relações.

Ademais, de acordo com os referenciais fenomenológicos, toda condição humana precisa ser compreendida sob a ótica dos fenômenos psicopatológicos, suspendendo parcimoniosamente dos dados clínicos oriundos da atividade científica tradicional, para tornar-se possível conhecê-lo a partir do campo existencial do sujeito (Foucault, 1975; Smith, Flowers \& Larkin, 2009). Como assinala Araújo (2010), a pessoa deve ser reconhecida em sua singularidade independente de sua condição patológica.

Ainda nesta perspectiva, Petrelli (2008) afirma que a fenomenologia se preocupa mais em desvelar o segredo das coisas, já que a ciência não é explicativa, mas sim descritiva, onde o objetivo não é a descoberta de causalidades, mas sim a possibilidade de compreensões das condições humanas. No entanto, o descobrimento de alterações do neurodesenvolvimento de uma criança, um dos momentos de maiores tensões vivenciados pela família, vem acompanhado do sentimento de culpa e da ânsia em explicar e identificar possíveis causas; e modificar os fenômenos psicopatológicos (Fávero \& Santo, 2005; Franco, 2016; Rehfeld, 2000).

De acordo com Petrelli (2008), o comportamento alheio não deve ser controlado ou mudado, mas sim compreendido, respeitado e acolhido em sua análise fenomênico-existencial, com seus significados e valores. Todavia, algumas famílias enfrentam dificuldades em assumir essa postura, pois como afirma Tinoco (2012) a frustração existencial, ainda que não seja considerada patológica, em muitas ocasiões não garante saúde mental.

Além disso, diante da condição de um diagnóstico do(a) filho(a) os pais se veem obrigados a abandonar as expectativas projetadas para a criança, criando novas, que possam incluí-la e comumente se colocam intensamente a serviço do desenvolvimento do filho, abdicando-se de sua própria história, em um movimento de viver a história da criança, alterando a qualidade de vida geral da família (Banach, Iudice, Conway \& Couse, 2010; Gadamer, 1993).

Dentre os impactos vividos pelas famílias que possuem crianças com TEA, os principais apontados 
pela literatura são: mudanças nos quesitos profissionais, diários, emocionais e pessoais (Kobasa, Hilkler \& Maddi, 1979). Os quais poderão mobilizar e até desorganizar as organizações das relações familiares, gerando estresse e alterações dos padrões de qualidade de vida (Sivberg, 2002).

Em consequência a esta condição, a QV dos pais sofre alterações, uma vez que ela está diretamente relacionada aos fatores psicológicos, físicos, sociais e ambientais que esta família está vivenciando. Como afirma Bom Sucesso (1997) e Minayo, Hartz e Buss (2000), QV é compreendida como resultado de percepções individuais, que variam de acordo com as experiências pessoais, os contextos e as áreas da saúde. Nesta perspectiva, pode-se afirmar que a QV é compreendida de acordo com a clarificação da obscuridade da existência de cada ser, pois o indivíduo só terá consciência de sua QV uma vez que estiver em contato e atribuir significados as situações que estiver exposto. Portanto, QV não é um estado, mas sim um processo que pode variar de acordo com as relações e vivências experienciadas de forma individual (Augras, 2004).

Nesse sentido, a QV das mães só poderá ser compreendida a partir da descrição da realidade, dos objetos e dos fatos, daquilo que emerge em suas consciências como significantes para compreensão de suas realidades (Petrelli, 2008). Portanto, as motivações e os déficits que o TEA poderá causar para a criança e para a família estão para além dos sintomas descritos, mas sim a serviço da subjetividade individual daqueles que estarão envolvidos em prol de um desenvolvimento, de uma aceitação e de uma busca de um equilíbrio holístico para a criança a para a família de forma geral.

Petrelli (2017) considera a maternidade como um evento social gerador de saúde. Uma vez que esse padrão é quebrado, torna-se fundamental a compreensão existencial que estas mães estão ofertando para si perante as suas realidades. Augras (2004) salienta que para a compreensão existencial necessita-se do encontro com a intersubjetividade, aprofundando o conhecimento sobre si próprio, não apenas para controlar os limites das atuações, mas também como possibilidade para o conhecimento e compreensão do outro.

Nesta vertente, Augras (2004) elege seis categorias existenciais a serem analisadas com a finalidade de auxiliar na compreensão da existência humana: a situação na qual a pessoa se encontra, seu campo existencial; a forma como lida com o tempo, tanto cronológico quanto vivido; a espacialidade como forma de experienciar a realidade do mundo; o outro visto tanto em si mesmo quanto naqueles com quem se relaciona; a linguagem que possibilita o contato; e a obra, ou seja, aquilo que o ser produz, não só materialmente, mas enquanto ser vivente.

Considerando o princípio da fenomenologia, este trabalho tem como objetivo primário descrever e compreender as construções subjetivs sobre a QV autorreferenciada de mães de crianças com TEA e como objetivo secundário realizar uma leitura fenomenoló- gica sob a ótica das seguintes categorias existenciais: a situação, o tempo, a espacialidade, o outro, a linguagem e a obra.

\section{Método}

\section{Delineamento do estudo}

Artigo empírico, descritivo, exploratório, com utilização do método qualitativo, especificamente do método fenomenológico de Giorgi (1985) e fundamentado a partir de uma leitura da psicopatologia fenomenológica (Augras, 2004).

\section{Local do estudo}

Este estudo foi desenvolvido no Centro de Atenção Psicossocial Água Viva e no Hospital das Clínicas da Universidade Federal de Goiás-Goiânia. A aplicação do questionário sociodemográfico e clínico e a realização das entrevistas semiestruturadas ocorreu em salas reservadas e consultórios dentro das instituições citadas.

\section{Participantes}

Trata-se de uma amostra de conveniência, constituída por 10 mães de crianças diagnosticadas TEA (apresentadas com nomes fictícios), usuárias dos serviços de saúde. Foram utilizados como critérios de inclusão, pessoas com filho (a) diagnosticado com TEA, entre dois a 12 anos de idade, que tivesse realizado acompanhamento nas instituições beneficiárias nos últimos 12 meses (2016/2017) e que aceitassem e assinassem o Termo de Consentimento Livre e Esclarecido (TCLE), aprovado previamente pelo Comitê de Ética de Pesquisa da PUC-GO. Como critérios de exclusão adotaram-se participantes diagnosticados com Transtornos Mentais e/ou que não respondessem adequadamente a todos os itens dos instrumentos utilizados pela pesquisa.

\section{Instrumentos}

Foram utilizados questionários de dados sociodemográficos e clínicos, composto por dezoito questões relativas à: nome, idade, estado civil, escolaridade, situação profissional, renda familiar do participante e aspectos clínicos sobre a criança (ano de diagnóstico, tipos de tratamentos, indicadores de comorbidades, medicamentos, dentre outros); Entrevista Semiestruturada sobre a Qualidade de Vida de Pais de Crianças com Transtorno do Espectro Autista composta por nove perguntas disparadoras, que abordaram temáticas tais como: qualidade de vida, diagnóstico do Transtorno do Espectro Autista e a relação entre elas.

\section{Procedimentos}

Primeiramente, a pesquisadora solicitou a permissão junto a Secretaria Municipal de Saúde - Superintendência de Administração e Gestão de Pessoas - responsável pelos serviços oferecidos no Centro de Atenção Psicossocial Água Viva e com o coordenador 
do Núcleo de Pesquisa - HC/UFG responsável pelos estudos realizados no Hospital das Clínicas da UFG. Após a permissão, solicitou-se a aprovação do Projeto de Pesquisa pelo Comitê de Ética de Pesquisa da Pontifícia Universidade Católica de Goiás (número CAAE: 58240116.4.0000.0037). Ambas as instituições beneficiadas disponibilizaram uma relação dos pacientes que utilizavam os serviços para apuração dos possíveis participantes para o estudo. A lista de mães que aparentemente se encaixavam dentro dos critérios de inclusão da pesquisa foi fornecida pela coordenadora do CAPS Água Viva.

Concluída esta etapa, a pesquisadora realizou contato, via telefone, para as pessoas que preencheram os critérios de inclusão elucidando sobre o objetivo do trabalho e indagando a respeito do interesse e disponibilidade para participar do estudo. $\mathrm{O}$ encontro com cada participante ocorreu individualmente, em salas reservadas, com duração média de 40 minutos, onde realizou-se a acolhida da participante e a leitura detalhada do TCLE reservando tempo para que a participante esclarecesse quaisquer dúvidas sobre a pesquisa e assinasse o termo. Em seguida, para o estudo qualitativo, a participante foi submetida ao questionário sociodemográfico e clínico e à entrevista semiestruturada baseada na metodologia de Giorgi (1985), que ocorreu por meio de nove perguntas disparadoras, sendo elas: 1) Para a senhora o que é ter uma vida com qualidade? 2) Como a senhora compreende a sua qualidade de vida? 3) Quais os principais fatores que tem favorecido a sua qualidade de vida? 4) Quais os principais fatores que tem desfavorecido a sua qualidade de vida? 5) Como a senhora percebe o diagnóstico do (a) seu/ sua filho (a)? 6) Qual o impacto que a senhora percebe que o diagnóstico de seu/sua filho(a) teve para sua família? 7) Qual a percepção da senhora sobre os tratamentos oferecidos ao seu/sua filho (a) pela instituição? 8) Como a senhora percebe sua qualidade de vida (QV) após o diagnóstico do (a) seu/sua filho (a) vivenciados até o momento? 9) Como a senhora percebe a sua qualidade de vida (QV) após os tratamentos do (a) seu/sua filho(a) vivenciados até o momento na instituição?

Concluída a etapa da coleta de dados, as entrevistas foram transcritas integralmente, garantindo o sigilo das participantes, analisadas segundo o método de pesquisa fenomenológica de Giorgi (1985) que segue os quatro passos de reduções fenomenológicas.

O primeiro passo proposto por Giorgi corresponde à leitura de toda a descrição, com o objetivo de alcançar o sentido do todo. Portanto, é necessário compreender a linguagem de quem fala, sem qualquer tentativa de identificar as unidades significativas. $\mathrm{O}$ segundo passo prevê a discriminação das unidades significativas, baseada na fenomenologia e focada no fenômeno. O pesquisador faz a releitura da transcrição na íntegra com o objetivo de discriminar as unidades de significado na perspectiva psicológica, focando no fenômeno pesquisado. Nesse passo, a linguagem do sujeito não é modificada, pois é essencial para o mé- todo que as discriminações ocorram antes e que sejam feitas espontaneamente, para depois serem interrogadas. No terceiro passo, transforma-se a fala do sujeito em uma linguagem psicológica, modificando a linguagem cotidiana do participante em linguagem psicológica apropriada com ênfase no problema estudado. No quarto e último passo, realiza-se a síntese das unidades significativas na qual o pesquisador sintetiza todas as unidades significativas em uma declaração consistente da significação psicológica dos fenômenos observados em relação à experiência do sujeito.

$\mathrm{O}$ método de Giorgi tem o intuito de identificar as unidades de significado que expressam o conteúdo temático dos depoimentos e, no presente artigo, as unidades identificadas foram correlacionadas com as categorias existenciais de Augras (2004).

\section{Resultado e Discussão}

Na Tabela 1 são apresentados os perfis de cada mãe participante e, na Tabela 2, as sínteses das entrevistas evidenciando-se as unidades de significado emergentes dos discursos ao desvelarem o fenômeno da qualidade de vida na condição de mães de crianças com Transtorno do Espectro Autista (TEA). Os dados são articulados, ainda, em sua interface com seis categorias existenciais, quais sejam: a situação, o tempo, a espacialidade, o outro, a linguagem e a obra (Augras 2004).

A Tabela 1 ilustra os perfis das mães participantes do estudo e também o quadro clínico do (a) filho (a) diagnosticado (a) com TEA. A partir desta descrição, torna-se possível identificar a singularidade vivenciada por cada mãe em relação às suas condições amorosas, educacionais, profissionais e financeiras.

Iniciando com as características descritas por cada mãe, a maioria são casadas. Nos quesitos educacionais, metade das participantes possuem ensino médio, enquanto a outra metade apresenta ensino superior, sejam eles incompletos ou completos. Este dado, pode estar relacionado com as condições profissionais e financeiras apontadas pelas mães participantes, onde a maioria delas relataram exercer um trabalho regular e possuir uma renda familiar de três a quatro salários mínimos.

Essas condições amorosas, educacionais, profissionais e financeiras, podem ser interrelacionadas para favorecer uma totalidade existencial das mães participantes do estudo. A condição de ter uma vida amorosa estável foi descrita pela maioria das mães participantes como uma condição para um melhor suporte emocional, físico e social, perante a realidade de ter um filho portador de TEA. O que está de acordo com a teoria proposta por Fávero e Santos (2005) que considera a união conjugal como uma possibilidade de construção de novas formas de perceber e vivenciar as limitações e as possibilidades da vida humana.

Ainda em relação com a condição amorosa, pode-se dizer que a situação educacional, profissional e fi- 
nanceira também está interligada. Uma vez que, ainda que algumas mães apresentem condições de trabalho, a maior parte da renda familiar é construída em conjunto com o parceiro, visto que algumas participantes relataram trabalhar com cargas horárias inferiores, pois para além do trabalho profissional, existem aqueles relacionados aos cuidados do lar e também do(a) filho(a). Direcionando para a oportunidade de trabalhar, é válido ressaltar que a capacidade para exercer essa função, pode ser um favorecedor da QV das mães participantes do estudo. Como afirmam Stoner e Stoner (2016) o trabalho pode ser compreendido como parte da própria identidade e como espaço de desenvolvimento do adulto. Uma vez que a pessoa se sente impossibilitada de exercer essa função, podem ser intensificados os níveis de estresse, desfavorecido as condições financeiras e até mesmo impactos nas relações amorosas (Yeargin-Allsopp, Rice, Karapurkar \& Doemberg, 2003).

Além destas condições humanas e singulares descritas por cada participante, os aspectos relacionados ao tempo de diagnóstico do(a) filho(a), os tratamentos terapêuticos e medicamentosos e a presença de comorbidades, também foram abordados. Uma vez que estes podem estar diretamente relacionados com a QV vivenciada por cada mãe participante deste estudo. De acordo com as mães participantes do estudo, a maioria delas relatam conviver com a condição de ter um filho diagnosticado com TEA a mais de três anos. Ainda que o TEA não seja considerado uma doença, mas sim um transtorno, na perspectiva da psicopatologia fenomenológica ele pode ser compreendido tanto a partir dos fenômenos sintomáticos como idiopáticos, todavia, resultante em uma diminuição da capacidade de estabelecer relações (Antony, 2012; Petrelli, 2017). Uma vez que esta realidade se faz presente, a necessidade de receber suporte terapêutico é necessária para auxiliar a criança e, também, a família a ter uma QV favorável. Todavia, as mães do estudo, frequentemente relatam que os suportes terapêuticos, na maioria das vezes, são direcionados para as crianças, com a ideia de favorecer as modificações dos comportamentos e amenizar os sintomas, considerados problemas.

Supõe-se que existe um olhar atentivo das políticas públicas para o desenvolvimento da criança, todavia ainda com ideias dicotomizadas e com intervenções que consideram apenas a criança como membro que necessita de intervenções terapêuticas, sem considerar usualmente, a QV das mães que necessitam levar a criança para as terapias e, muitas vezes, não recebem as orientações e o suporte adequado para expandir os cuidados decorrentes dos centros terapêuticos.

Como afirma a teoria de Kobasa et al. (1979) e Sivberg (2002) o diagnóstico de TEA pode trazer diversos impactos na QV das famílias, sejam eles físicos, psicológicos, ambientais e/ou sociais, gerando estresses, variações das experiências pessoais e alterações dos padrões de vida. Em interface com a fenomenologia, torna-se evidente que o TEA não é uma psicopatologia individual da criança, mas sim familiar, necessitando, portanto, ser compreendida sob essa ótica maior. Essa concepção do TEA ainda é acrescentada por Petrelli (2017) como uma condição para além do âmbito familiar, e sim cultural.

Baseado nos dados obtidos neste estudo, percebe-se que a maioria das mães descrevem que os filhos estão em terapia ou fazendo o uso de medicamentos. Todavia, nenhuma cita estar em terapia e tão pouco estar recebendo o suporte terapêutico adequado para favorecer uma melhor QV para si e para sua família de forma geral, embora ainda algumas citam, que quando necessário a equipe multidisciplinar do serviço oferece suporte. Neste contexto, observa-se ainda uma visão individualizada para a criança, onde a leitura de seu transtorno ainda é realizada de forma isolada, sem considerar os possíveis impactos que ele pode estar causando no ambiente familiar.

Nesta perspectiva, comprova-se que as objetividades dos tratamentos das crianças são mais valorizadas do que a subjetividade atribuída por cada perante as suas próprias necessidades e sua QV. Até mesmo no discurso da maioria das mães é possível observar o quanto a necessidades delas olharem para elas mesmas se tornam inferiores a partir da necessidade de oferecer um tratamento para o filho. Um dos exemplos que elucida a prioridade atribuída às necessidades da criança é o discurso da participante P8 - Tatiana: "Num tem como eu me dedicar a outra coisa, a estudar ou até mesmo trabalhar, não tem como. O período da tarde é todo pra ele. (...)”.

Em contrapartida, existem também aquelas mães que fazem uma leitura favorável perante as estimulações terapêuticas do filho, pois, ainda que a rotina seja árdua e o estresse seja intenso devido a exaustão, o tratamento pode trazer para as mães a oportunidade de terem um tempo para si, a esperança do desenvolvimento do filho e consequentemente uma melhor QV, uma vez que ver as dificuldades do filho traga impactos significativos. Divina, participante P2 demonstra essa afirmação quando expõem:

No começo das terapias era muito difícil, (...) ele não ficava (...) era quinze minutos e o profissional me chamava. (...) hoje ele fica quarenta minutos (...) consigo ter um tempo para mim, (...) enquanto ele está sendo atendido. (...) porque tem hora que cansa (...) mais ele tá aprendendo a concentrar (...) está muito melhor (...).

De acordo com o pensamento de Banach et al. (2010) e Gadamer (1993) é compreensível que mães se coloquem intensamente a serviço do desenvolvimento do filho. Entretanto, ainda que essa seja uma escolha da mãe, não assegura um não impacto na QV, uma vez que ela está relacionada aos aspectos subjetivos e intimamente relacionada com o significado atribuído individualmente. 


\section{Tabela 1}

Descrição do perfil das mães de crianças com Transtorno do Espectro Autista, considerando os aspectos sociodemográficos e os aspectos clínicos das crianças (nomes fictícios).

\begin{tabular}{|c|c|}
\hline Part. & Perfil \\
\hline $\mathrm{P} 1$ & $\begin{array}{l}\text { Rose, } 30 \text { anos, casada, possui ensino médio completo, é manicure autônoma em um salão } \\
\text { meio período e o restante do dia se considera empregada dos filhos. Mora em casa alugada } \\
\text { e dispõe de uma renda mensal de um a dois salários mínimos. Miguel, filho de Rose, de seis } \\
\text { anos, foi diagnosticado com TEA e com Epilepsia de difícil controle com menos de dois anos } \\
\text { de idade. A criança encontra-se em acompanhamento neurológico, fonoaudiológico, } \\
\text { fisioterápico e de hidroterapia. Faz uso de medicação desde antes do diagnóstico para } \\
\text { controle das crises convulsivas e comportamentais. }\end{array}$ \\
\hline P2 & $\begin{array}{l}\text { Divina, } 29 \text { anos, casada, possui ensino superior completo, é cabeleireira autônoma, } \\
\text { possui uma renda de um a dois salários mínimos por mês, é mãe de Enrico, oito anos, } \\
\text { diagnosticado com TEA aos seis anos de idade, possuindo como comorbidade Transtorno } \\
\text { Obsessivo Compulsivo e Hiperatividade. A criança encontra-se em acompanhamento } \\
\text { fonoaudiológico, neurológico, psicológico e com estimulação de arte terapia há dois anos. } \\
\text { Faz uso contínuo de medicamentos. }\end{array}$ \\
\hline P3 & $\begin{array}{l}\text { Vanessa, } 36 \text { anos, casada, tem o ensino médio completo, não trabalha fora de casa e possui } \\
\text { menos de um salário mínimo por mês. Matheus, filho de Vanessa, tem sete anos de idade e } \\
\text { foi diagnosticado com TEA, possuindo como comorbidade Déficit Cognitivo Modulado aos } \\
\text { dois anos de idade. Desde o diagnóstico, a mãe busca tratamento com psicóloga e } \\
\text { fonoaudióloga para o filho, porém, como ele é muito agressivo, as terapias são iniciadas e } \\
\text { logo as profissionais relatam que não conseguem atuar com a criança, deixando-a apenas } \\
\text { com acompanhamento neurológico e com terapias medicamentosas para controlar a } \\
\text { agressividade. }\end{array}$ \\
\hline P4 & $\begin{array}{l}\text { Luciana, } 34 \text { anos, casada, possui ensino médio completo, não trabalha e tem uma renda } \\
\text { familiar de dois a quatro salários mínimos por mês. André, seis anos, diagnosticado com } \\
\text { TEA aos três anos de idade, sem outra comorbidade, realiza acompanhamentos com } \\
\text { neuropediatra, fonoaudióloga, musicoterapeuta, pedagoga, psicomotricista e aula de } \\
\text { natação desde o ano do diagnóstico. }\end{array}$ \\
\hline P5 & $\begin{array}{l}\text { Rosangela, } 37 \text { anos, divorciada, é pós-graduada, concursada e atua como servidora pública } \\
\text { estadual. Reside apenas com o filho e possui uma renda superior a quatro salários mínimos. } \\
\text { Pedro, sete anos, foi diagnosticado com TEA de grau leve aos quatro anos de idade e há } \\
\text { três anos realiza acompanhamentos frequentes com neuropediatra, musicoterapeuta, } \\
\text { psicóloga, fonoaudióloga e terapeuta ocupacional. Faz uso de medicamento duas vezes ao } \\
\text { dia para melhorar a atenção e não possui outras comorbidades. }\end{array}$ \\
\hline P6 & $\begin{array}{l}\text { Catarina, } 29 \text { anos, divorciada, possui ensino médio incompleto e não atua em nenhuma área } \\
\text { de trabalho. Dispõe de uma renda mensal de um a dois salários mínimos e é mãe de Caio, } \\
\text { de seis anos de idade. Sua gestação não foi planejada, porém, foi aceita por ela. Todavia, } \\
\text { com quatro meses de gestação, o pai da criança a abandonou, pedindo para que ela } \\
\text { escolhesse entre ele ou o filho. Caio foi diagnosticado aos três anos com TEA, sem outra } \\
\text { comorbidade. Desde então faz acompanhamento neurológico e psiquiátrico, além das } \\
\text { estimulações com pedagoga, psicomotricista, psicóloga e educador físico com ênfase em } \\
\text { aulas de natação. Faz uso de diversos medicamentos para controle dos comportamentos, } \\
\text { principalmente da inquietação motora. }\end{array}$ \\
\hline P7 & $\begin{array}{l}\text { Jaqueline, } 33 \text { anos, amasiada, concluiu o ensino médio, trabalha apenas nas atividades do } \\
\text { lar e dispõe de uma renda mensal de dois a quatro salários mínimos. Joaquim, filho de } \\
\text { Jaqueline, atualmente tem } 10 \text { anos de idade, nasceu na Espanha e retornou ao Brasil } \\
\text { quando tinha quatro anos de idade. Na mesma idade, foi diagnosticado com TEA e iniciou } \\
\text { os acompanhamentos neurológicos, psiquiátricos e pedagógicos. Joaquim não faz uso de } \\
\text { fármacos. }\end{array}$ \\
\hline P8 & $\begin{array}{l}\text { Tatiana, } 34 \text { anos, casada, possui ensino superior incompleto, atua como agente } \\
\text { educacional e possui uma renda de dois a quatro salários mínimos mensais. João, quatro } \\
\text { anos, tem diagnóstico de TEA, sem comorbidades, desde os dois anos de idade e realiza } \\
\text { terapias fonoaudiológicas, terapias ocupacionais, pedagógicas e farmacológicas há um } \\
\text { ano. }\end{array}$ \\
\hline P9 & $\begin{array}{l}\text { Raquel, } 34 \text { anos, casada, concluiu o ensino superior, é pedagoga concursada e dispõe de } \\
\text { uma renda de dois a quatro salários mínimos por mês. Amanda, } 12 \text { anos, foi diagnosticada } \\
\text { aos três anos e meio com TEA severo, sem outras comorbidades, e desde então, faz } \\
\text { acompanhamentos frequentes com neurologistas e psiquiatras, além de fazer uso de }\end{array}$ \\
\hline
\end{tabular}


Direcionando para uma síntese das entrevistas das participantes, a Tabela 2 elucida as seis categoriais existenciais propostas por Augras (2004). Quanto a categoria existencial "a situação", Augras (2004) a descreve como a maneira individual que cada pessoa encontra para estar em contato com o mundo humano, próprio e circundante, como afirma a teoria existencialista de Binswanger (1977). De acordo com Holanda (2014) compreender o homem perpassa pela sua contextualização existencial, como um ser de relações mundanas e transcendentes. Em concordância, Petrelli (2008) explica que a existência humana precisa ser compreendida a partir da realidade individual, pois o fenômeno possui uma singularidade inesgotável de criatividade. Portanto, ainda que ter um(a) filho(a) diagnosticado(a) com TEA seja comum entre as participantes, o significado desta realidade e a influência em suas QV são vivenciados de maneira particular.

As participantes Luciana (P4) e Raquel (P9) ilustram isso com clareza quando apresentam compreensões diferentes perante a condição existencial do filho. Luciana (P4) diz:

é um choque. (...) Eu não sabia o que seria o autismo. Hoje (...) que eu saiba é um transtorno que afeta os neuro da criança. (...) na verdade eu sei muito pouco de autismo para uma mãe de autista. Na verdade, eu não sei nada. A gente não tem acompanhamento (...).

Em contrapartida, o significado e a criatividade de Raquel (P9) percorreu caminhos diferentes. A participante diz:

Por muito tempo foi como impossibilidade (...) eu transformei isso em possibilidade. O diagnostico dela me levou a querer fazer uma faculdade. (...) o diagnostico dela ao mesmo tempo que é chocante e é uma coisa muito ruim pra gente e pra família, (...). Minha filha precisa de mim, (...) a base é ela. E é isso que me dá força. Uma frase pra definir o diagnostico é a possibilidade que eu tive de buscar, de ir atrás de conhecimento, (...).

Para além destes trechos relacionados à compreensão individual do diagnóstico, as subjetividades expressadas por cada mãe participante do estudo, também se fizeram presentes na compreensão da QV assim como ilustra a Tabela 2 .

De acordo com a Tabela 2, é possível identificar e compreender que cada mãe apresenta aquilo que mais emerge em si quando o tópico de investigação é a QV em interface com a condição de ter um(a) filho(a) com TEA. Dentre as categorias existenciais propostas por Augras (2004) como a situação se refere a condição existencial que cada pessoa se encontra, ela foi identificada e considerada emergente em todos os discursos. Seguido desta categoria, as duas outras que mais emergiram nas falas das mães foram: a obra e o outro, e a menos citada foi o tempo.

Traduzindo para uma leitura fenomenológica, pode-se compreender que cada mãe apresenta sua intencionalidade, ainda que as variáveis disparadoras sejam as mesmas. Ribeiro (1985) considera a intencionalidade como um movimento transcendente de atribuir sentido e significado as coisas.

Neste estudo, identificou-se que as intencionalidades das mães, de uma forma geral, podem ser compreendidas a partir das categoriais existenciais apresentadas com maiores frequências, sendo elas: "obra” e "outro". Iniciando com a categoria " a obra”, Augras (2004) a define como além de produções materiais; trata-se de uma obra implícita de um fazer contínuo do processo da vida. Nesta perspectiva o homem é sua própria obra e sua própria construção. Relacionando com a realidade contextual das mães participantes do estudo, ter um(a) filho(a) com TEA faz parte de seus campos existenciais, todavia, todas elas são livres e responsáveis pelas construções e significados que este diagnóstico terá em sua QV de forma geral.

Portanto, a partir de uma leitura fundamentada na psicopatologia fenomenológica, ainda que o TEA possua uma compreensão sintomatológica, sua real compreensão se dá após a clarificação do significado obscurecido da cada família que está vivenciando tal condição existencial e identificar as possibilidades de cada pessoa encontra para construir suas próprias obras.

Jaqueline (P7) exemplifica sua obra frente o diagnóstico do filho e a forma como conseguiu ressignificá-lo, substituindo possíveis sentimentos de culpas, que impactariam sua QV para sentimentos de oportunidades, que favorecem a leveza de caminhar adiante ao relatar:

(...) quando surgiu o diagnóstico, tudo mundo ficava tipo: nossa, porque? (...) de onde vem, porque ele é especial (...) você é culpada. E foi mesmo impactante (...) hoje não (...) então assim, eu não sinto culpa, eu sinto escolhida, eu não me sinto culpada (...) o diagnóstico veio tirar uma dúvida da minha cabeça (...) sabia que meu filho não era igual minha outra filha (...) assim, eu fui escolhida para ter uma criança especial (...).

Em relação com a capacidade de estar em processo de vida, buscando sempre uma forma mais saudável e equilibrada para favorecer a QV, está a categoria existencial - "outro”, que também foi transmitida por boa parte das participantes, e está em relação com a necessidade de cuidar de si, do outro, neste caso o filho, e receber suporte social. Todavia, boa parte das mães expõem a incapacidade destes cuidados serem prioritários para si, uma vez que a condição existencial do filho, gera mudanças significativas nas prioridades e nas funções maternas. 


\section{Tabela 2}

Síntese das entrevistas em relação a Qualidade de Vida (QV) de cada mãe de criança com Transtorno do Espectro Autista e as categoriais existenciais emergentes de acordo com a proposta de Augras (2004).

\begin{tabular}{|c|c|c|}
\hline Part. & Síntese da Entrevista & Categoria \\
\hline $\mathrm{P} 1$ & $\begin{array}{l}\text { Para Rose, QV é ter moradia própria, oferecer cuidados aos filhos, ter } \\
\text { possibilidade de trabalhar, divertir e ter saúde. O que favorece sua QV } \\
\text { é sentir-se capaz de cuidar dos filhos, ter seu próprio dinheiro e ajudar } \\
\text { seu marido com as despesas. O que desfavorece é refletir sobre as } \\
\text { oportunidades que desperdiçou no quesito de trabalho e finanças. } \\
\text { Quanto ao quadro de saúde do filho, Rose considera que os cuidados } \\
\text { são muito fáceis. O período do diagnóstico foi difícil, devido ao } \\
\text { péssimo prognóstico para Miguel. Todavia, para Rose, o que causou } \\
\text { grandes mudanças, foi a necessidade de ajustar-se criativamente } \\
\text { para se adequar as necessidades de seu filho. Após as intervenções, } \\
\text { Rose sente-se grata aos tratamentos e a forma como é acolhida nas } \\
\text { instituições, o que considera como fator favorecedor de sua QV. }\end{array}$ & $\begin{array}{ll}\text { - } & \text { Outro } \\
\text { - } & \text { Obra }\end{array}$ \\
\hline $\bar{P} 2$ & $\begin{array}{l}\text { Divina, acredita que ter uma vida de qualidade é ter um tempo para si } \\
\text { e para o esposo na ausência dos filhos, mas relata não ser possível } \\
\text { porque o filho não permite ser cuidado por outra pessoa, devido a } \\
\text { tamanha dependência do filho em situações simples como: tomar } \\
\text { banho, trocar de roupa, Divina compreende sua QV como mais ou } \\
\text { menos, tendo consciência que o que mais a desfavorece são as } \\
\text { sobrecargas do mundo humano e os incômodos ambientais } \\
\text { constantes, principalmente os barulhos e choros. Em contrapartida, } \\
\text { Divina diz que levar a vida na brincadeira, sem focar nas dificuldades, } \\
\text { é o que lhe ajuda a ter uma vida com um pouco de qualidade. }\end{array}$ & $\begin{array}{ll}- & \text { Tempo } \\
\text { - } & \text { Outro } \\
\text { - } & \text { Espacialidade } \\
\text { - } & \text { Obra }\end{array}$ \\
\hline P3 & $\begin{array}{l}\text { Vanessa acredita que ter uma vida de qualidade é ter a oportunidade } \\
\text { de um trabalho digno, para assim, conseguir proporcionar tratamento } \\
\text { adequado ao filho e ter um meio de transporte melhor. Para P3, não } \\
\text { há nada que favoreça sua QV, pois desde o nascimento de seu filho, } \\
\text { devido a ausência de suporte social, Vanessa não pode retornar ao } \\
\text { trabalho, e com isso sua QV foi diretamente afetada. Atualmente as } \\
\text { únicas estratégias que amenizam as dificuldades de Vanessa nos } \\
\text { cuidados com o filho são as terapias medicamentosas que estão } \\
\text { controlando parcialmente a agressividade dele. }\end{array}$ & $\begin{array}{ll} & \text { Outro } \\
\text { - } & \text { Obra } \\
\text { - Tempo }\end{array}$ \\
\hline $\mathrm{P} 4$ & $\begin{array}{l}\text { Para Luciana QV é viver bem, ter sucesso e progredir. Quando se alto } \\
\text { referencia, Luciana diz que sua QV está comprometida } \\
\text { principalmente no domínio físico: cansaço/estresse, dependência de } \\
\text { tratamentos para o filho. Além de afirmar que na convivência extrema } \\
\text { com alguém autista, muitos comportamentos se tornam semelhantes } \\
\text { e também acarreta um desgaste emocional devido a intensidade dos } \\
\text { cuidados. Perceber o diagnóstico do filho foi um choque, abalando } \\
\text { inclusive seu casamento. Por outro lado, recebeu o apoio de seu } \\
\text { esposo e familiares em gerais. Luciana acredita que sua QV é } \\
\text { proporcional ao seu conhecimento sobre o TEA e também a evolução } \\
\text { de seu filho. André está melhor após os tratamentos oferecidos, } \\
\text { porém, o dia-a-dia ainda está estressante para Luciana. }\end{array}$ & $\begin{array}{ll}\text { - } & \text { Espacialidade } \\
\text { - } & \text { Outro }\end{array}$ \\
\hline P5 & $\begin{array}{l}\text { Para Rosangela, QV é viver e fazer parte de uma rede social com } \\
\text { funções para cumprir; é ter estabilidade emocional, profissional, } \\
\text { comportamental e relacional. Lidar com as instabilidades do filho é } \\
\text { desconfortante e gera uma ansiedade que atrapalha sua QV. Todavia, } \\
\text { hoje consegue agradecer a Deus pela presença de seu filho, pois está } \\
\text { aprendendo a conviver com as diferenças sem descartá-las. } \\
\text { Entretanto, percebe que está perdendo sua identidade, devido as } \\
\text { adaptações realizadas para o filho. Nestes paradoxos, Rosangela vive } \\
\text { uma constante busca da aceitação da condição de Pedro. O } \\
\text { diagnóstico foi o pior momento da vida; afetou a família de forma } \\
\text { geral e os suportes sociais. O lugar onde Rosangela encontrou } \\
\text { acolhimento, perante a tantos momentos de angustias, foi nos } \\
\text { centros de tratamento do filho. }\end{array}$ & $\begin{array}{ll}\text { - } & \text { Tempo } \\
\text { - } & \text { Outro } \\
\text { - } & \text { Espacialidade } \\
\text { - } & \text { Linguagem }\end{array}$ \\
\hline
\end{tabular}




\begin{tabular}{|c|c|c|}
\hline P6 & $\begin{array}{l}\text { Para Catarina QV é suprir as necessidades básicas, ter tempo para } \\
\text { cuidar de si, receber suporte social e profissional e ter momentos de } \\
\text { lazer. Nenhum destes tópicos é experienciado por ela, portanto, } \\
\text { considera sua QV comprometida. Além destes prejuízos, não ter casa } \\
\text { própria e precisar morar de favor em um cômodo da casa da mãe, } \\
\text { dividido com três criança é estressante. Quanto ao diagnóstico de } \\
\text { TEA do filho, Catarina diz não compreender, mas que o impacto foi } \\
\text { grande, acarretando uma profunda depressão, necessária a recorrer } \\
\text { a medicações. Com os tratamentos corretos, Catarina relata que no } \\
\text { dia-a-dia, quando o filho está frequente nas terapias, o percebe mais } \\
\text { calmo. }\end{array}$ & $\begin{array}{ll}\text { - } & \text { Linguagem } \\
\text { - } & \text { Obra } \\
\text { - } & \text { Outro }\end{array}$ \\
\hline $\mathrm{P} 7$ & $\begin{array}{l}\text { Para Jaqueline QV é reduzir as tensões e aumentar os suportes } \\
\text { sociais. O diagnóstico de TEA do filho, trouxe muito impacto na sua } \\
\text { QV, pois a família do esposo busca explicações, frequentemente a } \\
\text { culpabilizando. Como fator favorecedor, Jaqueline descreve que é a } \\
\text { força que sai de dentro de si para aproveitar cada oportunidade que é } \\
\text { ofertada pela vida; o suporte social oferecido pelos profissionais que } \\
\text { acompanham Joaquim e até mesmo o diagnóstico, pois este veio } \\
\text { para confirmar uma percepção da mãe e também para lhe fazer } \\
\text { sentir-se especial por ser escolhida para essa missão. Jaqueline } \\
\text { afirma ter inúmeras dúvidas acerca do diagnóstico de TEA. }\end{array}$ & $\begin{array}{ll}\text { - } & \text { Espacialidade } \\
\text { - } & \text { Outro } \\
\text { - } & \text { Linguagem }\end{array}$ \\
\hline P8 & $\begin{array}{l}\text { Para Tatiana, não ter tempo para cuidar de si e o baixo suporte social } \\
\text { desfavorecem sua QV. Os tratamentos intensos do filho com TEA lhe } \\
\text { consome muito tempo e com isso a atenção ao outro filho fica } \\
\text { comprometida. Para ela, o diagnóstico é percebido no dia-a-dia, } \\
\text { devido as particularidades comportamentais do filho. A falta de } \\
\text { conhecimento de sua família a respeito do autismo, fez com que, } \\
\text { inicialmente não aceitassem o diagnóstico de seu filho. Atualmente } \\
\text { Tatiana percebe uma melhora parcial na sua QV, devido as condições } \\
\text { de trabalho, meio de transporte e por estar tendo um tempo livre para } \\
\text { dar atenção ao seu outro filho. Todavia, afirma que sua QV poderia } \\
\text { ser melhor se os tratamentos oferecidos fossem mais eficientes. }\end{array}$ & $\begin{array}{ll}- & \text { Tempo } \\
\text { - } & \text { Linguagem } \\
\text { - } & \text { Obra }\end{array}$ \\
\hline P9 & $\begin{array}{l}\text { Raquel diz que QV é ter boa saúde; discriminar o que é desejo de } \\
\text { necessidade; e buscar enxergar o que há de positivo em cada } \\
\text { contexto. Sua QV está boa, pois trabalha, passeia e recebe suporte do } \\
\text { esposo. O TEA foi uma condição limitadora, mas a família buscou } \\
\text { formas de autorregular para amenizar os impactos. Ainda que Raquel } \\
\text { receba o apoio do esposo, existem momentos de frustração com as } \\
\text { limitações da filha, que desfavorecem sua QV. O diagnóstico foi difícil } \\
\text { e acarretou mudanças nas relações familiares. Raquel compreende } \\
\text { que a QV de seus outros filhos ficou prejudicada devido às limitações } \\
\text { de sua filha diagnosticada com TEA. Uma das estratégias para } \\
\text { melhorar a QV da família foi a inserção de terapias medicamentosas } \\
\text { para Amanda (TEA), que serviram de apoio para acalmá-la, e ajustar } \\
\text { seus comportamentos. }\end{array}$ & $\begin{array}{ll}\text { - } & \text { Obra } \\
\text { - } & \text { Linguagem } \\
\text { - } & \text { Espacialidade }\end{array}$ \\
\hline P10 & $\begin{array}{l}\text { Para Juliana QV é estar bem com a família, consigo mesma e com o } \\
\text { trabalho. Sua QV é influenciada pelas intensidades e frequências de } \\
\text { suas preocupações. Dentre elas a faculdade, os cuidados com o filho, } \\
\text { a ausência de tempo para cuidar de si e até mesmo existir. O que } \\
\text { favorece sua QV é estabelecer relações afetivas com as pessoas e } \\
\text { vivenciar os avanços de seu filho. Desde o diagnóstico, Juliana relata } \\
\text { ter conhecimento sobre as limitações e habilidades de seu filho, o que } \\
\text { Ihe conforta diariamente. Todavia, ainda considera que não sabe } \\
\text { muito sobre o autismo, mas afirma que ele favoreceu sua QV. Graças } \\
\text { com diagnóstico, Rodrigo (TEA) recebe os tratamentos adequados - } \\
\text { terapia e medicação e a QV de Juliana melhorou. }\end{array}$ & $\begin{array}{ll} & \text { Obra } \\
- & \text { Tempo } \\
\text { - } & \text { Outro } \\
\text { - } & \text { Linguagem }\end{array}$ \\
\hline
\end{tabular}


Ainda nesta perspectiva de estar em relação com o outro, muitas mães queixam da dificuldade encontrada nos suportes sociais, uma vez que as ajudas e as compreensões não acontecem de acordo com as expectativas delas. Vanessa, P3, demonstra que sua QV é afetada nesta dimensão ao dizer:

(...) eu não tenho com quem deixar ele pra sair pra trabalhar, (...) passei em concurso público, depois que ele nasceu eu fui chamada e não teve como eu ir, (...) desde que ele nasceu tudo desfavorece minha qualidade de vida. Tudo porque eu não tenho quem olha ele (...).

No discurso de Vanessa fica evidenciado o peso das construções sociais perante a construção de uma QV saudável. O que também fica claro na categoria existencial "o outro" postulado como o mundo da coexistência e não da oposição ou da complementaridade, Augras (2004), ainda, afirma que o outro não é aquilo que eu não sou, pelo contrário, os outros são aqueles dos quais a gente não se distingue, mas se encontra. Em união a esta categoria, existe a "linguagem", definida por Augras (2004) como criação e organização do mundo a partir das compreensões individuais e essenciais do existir humano.

Adotando tal perspectiva, admite-se que o ser humano é visto como um ser integrado e em formação, o que remete a compreensão filosófica apontada por Sartre (2012) "a existência precede a essência", significando que o homem surge no mundo como um ser particular, sem possibilidades de definição prévia, podendo vir a ser, por meio das relações estabelecidas, um ser livre para fazer escolhas, consumando seu projeto de vida de ser-no-mundo (Ginger \& Ginger, 1995; Ribeiro, 1985; Yontef, 1998).

Rosangela (P5) descreve a significância de estar em contato com seu filho diagnosticado com TEA para a construção, formação e transformação, não apenas de sua qualidade de vida, mas também do seu ser de forma total, pois, diariamente aprende com seu filho e desenvolve percepções que até então não tinha sentido em sua vida.

(...) os pais ficam um pouco autistas também, cê vive tanto isso, que pra você é natural (...) cê vai desenvolvendo outros sentidos. (...) Eu comecei a ouvir mais as pessoas, ouvir os sons, (...) ele gosta muito de fenômeno da natureza, (...) ele não conseguia entender como que podia chover e ter sol ao mesmo tempo. (...) você vai entrando nesse pensamento e você vê que é um pensamento bem profundo das coisas, porque a gente fica tão no automático (...) ele tem me mostrado que o que importa é ser feliz. (...) Igual, esse natal ele pediu nas cartinhas, seis reis. (...) Comprei mais umas coisas como se fosse o papai Noel tentando fazer com que ele entendesse a simbologia da coisa, aí eu falei "olha meu filho e tal... que bom que o papai Noel te trouxe umas coisas, aí ele falou: "pois é mãe, ele enganou porque eu só pedi isso". (...) foi mais uma necessidade minha (...).

A partir da relação entre os aspectos teóricos e a ilustração do trecho da entrevista de Rosângela, identifica-se que ainda que o mundo aparenta se apresentar de forma igualitária a todos, a sensibilidade para apreciá-lo é individual. E também que, ainda que estar em relação diária com uma criança diagnosticada com TEA possa ser desafiador, Rosangela atribui a esse contato uma possibilidade para se transformar e consequentemente favorecer sua qualidade de vida em outras dimensões.

Para além das compreensões dos processos de vida, das relações sociais, existe também duas categoriais imprescindíveis para favorecer que a QV seja desenvolvida nestas dimensões, sendo elas: a espacialidade e a temporalidade, além de estarem em constante sintonia, estão também em harmonia com o outro, pois as relações se dão em suas totalidades e apenas neste eixo torna-se possível a compreensão da existência humana.

A "espacialidade" (Augras, 2004), a qual é constituída a partir das extensões do corpo e inclui o mundo - compreendido como sítio humano que é orientado e dimensionado pelo homem, não como uma ordem, mas como um processo de construção como forma de experienciar a realidade. Ainda nesta perspectiva, Costa (2008) considera a espacialidade como modos da pessoa estar no espaço. Todavia, a autora afirma que o espaço não se caracteriza como um recipiente, mas como espacialidade que se estende conforme as ações são efetuadas e de acordo com a tomada de consciência e do sentido atribuído individualmente e também socialmente. Assim, para Raquel (P19):

(...) sem a medicação a gente já passou noite terríveis assim, de terror mesmo de ir polícia na nossa casa, achando que a gente tava matando alguém de tanto que ela ficou agressiva e violenta, e ela tinha bem menos idade, ela tinha oito anos, agora ela já tá com doze, então ela melhorou muito a questão do comportamento, não mudou na questão da aprendizagem, eu não digo ela tem aprendido porque ela continua muito dependente, mas na questão de ficar mais calma, de dormir pelo menos, que a gente não dormia.

Ainda na intenção de compreender o sentido e o significado que as mães apresentam em relação a suas QV, Augras (2004) define a categoria existencial "o tempo" não como uma dimensão do mundo, mas como uma orientação significativa do ser. Portanto, analisar o tempo é observar o homem em sua contradição entre a permanência e a transitoriedade; poder 
e impotência; vida e morte. Holanda (2014) aponta que o tempo, no caso da fenomenologia, a temporalidade, desempenha uma função crucial para a compreensão da consciência, por ser o elemento unificador das estruturas vivenciais. Em concordância, Costa (2008) descreve que o tempo não significa o tempo em si, mas os modos que as pessoas vivem temporalmente, construindo espacialidades e temporalidades.

Portanto, compreende-se que o tempo não é imutável, ele é alterado e transformado de acordo com os significados e as experiências vivenciadas por cada pessoa. Juliana, participante P10, elucida sua forma de vivenciar o tempo quando diz:

(...) o tempo pra mim mesmo eu ainda não tenho, e eu uso a palavra ainda porque eu sei que eu vou ter, (...) precisa melhorar meu tempo, mas é tudo questão de tempo, (...) eu preocupo muito, foco muito na criança, as vezes eu percebo que assim, é como se eu vivesse só ele (...) mas como ser diferente né? (choro) Desculpa. (...) eu gosto muito de tá cuidando de mim, ter tempo pra mim, ir em uma academia, dançar, tava com o peso controlado, essas coisas de questão pessoal mesmo né, mas tudo tem um tempo, (...) mas não fico prostrada não, porque a vida tá aí, a gente tem que correr atrás(....) falo para o meu esposo, o que a gente tiver que fazer pelo Rodrigo nós dois, tem que fazer agora, porque a gente tem mais disposição, mais tempo, mais saúde, e vai ser melhor pra ele, porque ele vai crescer e vai ter uma qualidade de vida, e o dia que a gente não tiver aqui ele vai ser mais independente, então eu acredito que daqui uns três anos a rotina nossa vai tá mais aliviada, eu sempre vivo nessa expectativa assim de que as coisas vão tá melhor.

É possível identificar que para Juliana, ainda que sua qualidade de vida seja prejudicada pela falta de tempo para cuidar de si; o cuidar do outro, em especial o filho com TEA lhe gera uma esperança de um futuro de qualidade para o filho. Segundo Banach et al. (2010) e Gadamer (1993) é comum que as mães se coloquem intensamente a serviço do desenvolvimento do filho, ainda que necessita abdicar de fatores importantes para si, neste caso, o tempo e modificar suas prioridades de vida no presente.

Correlacionando o exemplo com a fenomenologia, Minkowski (1973) considera que o tempo é vivido de forma individual, ainda que existe o tempo cronológico, universal para todos. Considerando a vivência do tempo, o autor afirma que todo indivíduo tem a possibilidade de experienciar, transcender, mensurar, quantificar e prever o tempo de acordo com as suas subjetividades, individualidades e necessidades. Portanto, torna-se compreensível, quando investigado a partir da ótica de Juliana, a ne- cessidade que ela tem hoje de escolher oferecer seu tempo, ainda que transmita a ideia de uma perda de sua QV, em detrimento da QV do filho.

\section{Conclusão}

Ainda que se busque um padrão para compreensão da QV e dos principais prejuízos vivenciados pelas mães de crianças com TEA, cada uma dispõe de fatores subjetivos que refletem em sua forma de experienciar a condição de ser mãe de uma criança com necessidades especiais. Encontrou-se na fenomenologia, a possibilidade de atribuir valor aquilo que é sentido, pensado e atribuído significado para cada mãe, em detrimento daquilo que é quantitativamente esperado.

Na perspectiva da psicopatologia fenomenológica, o TEA é vivenciado em uma dimensão maior do que apenas as características sintomatológicas apresentadas pela criança. O cerne da compreensão do TEA está no olhar atentivo as características idiopáticas; as escolhas, liberdades e responsabilidades que cada mãe que está na condição de exercer a maternidade de um(a) filho(a) nestas condições existenciais fazem de suas QV nas dimensões físicas, psicológicas, sociais e ambientais.

Para além da compreensão do significado do diagnóstico e dos quadros comportamentais da criança, a mãe precisa ser acolhida e considerada em sua forma de vivenciar esse encontro com seu/sua filho(a), sendo adequado uma leitura compreensiva e descritiva, em oposição a uma leitura interpretativa e assertiva em busca de padrões de respostas. Por isso, encontrou-se nas categoriais existenciais propostas por Augras (2004) a possibilidade de atribuir voz aos sentimentos e significados descritos pelas mães. As categorias existenciais escolhidas apontam para formas de ser e estar no mundo, porém, respeitando as possibilidades e as limitações individuais.

Portanto, a leitura baseada a partir da fenomenologia psicopatológica, demonstra que a ciência ao buscar compreender a QV de pessoas com características similares, também considera a relevância dos aspectos subjetivos e o significado que cada mãe constrói de sua própria realidade, pois, nesta perspectiva, é aceitando a pessoa com suas dores e alegrias, seus pesadelos e sonhos, suas limitações e potencialidades, que torna-se acessível auxiliá-la na tomada de consciência para favorecer sua qualidade de vida. 


\section{Referências}

Antony, S. (2012). Gestalt-terapia: cuidando de crianças - Teoria e arte. Curitiba: Juruá.

Araújo, A. M. L. (2010). O diagnóstico na abordagem fenomenológica-existencial [versão eletrônica]. Revista IGT na rede, 8, 315-323.

Associação Americana de Psiquiatria. (2014). Manual diagnóstico e estatístico de transtornos mentais ( $5^{\mathrm{a}}$ Ed., M. I. C. Nascimento, P. H. Machado, R. M. Garcez, R. Pizzato e S. M. M. Rosa, trad.). Porto Alegre: Artmed.

Augras, M. (2004). O ser da compreensão: fenomenologia da situação de psicodiagnóstico. São Paulo: Vozes.

Banach, M., Iudice, J., Conway, L., \& Couse, L. (2010). Family Support and Empowerment: Post Autism Diagnosis Support Group for Parents. Social Work With Groups, 33(1), 69-83. http://dx.doi.org/10.1080/01609510903437383

Binswanger, L. (1977). El caso de Ellen West: Estudio antropológico-clínico. In R. May, E. Angel \& H. Ellenberger (Orgs.), Existencia (pp. 288-434). Madrid, España: Gredos.

Bom Sucesso, E. de P. (1997) Trabalho e qualidade de vida. Rio de Janeiro: Dunya.

Costa, V. E. S. M. (2008). Compreendendo o Tempo Vivido Por Adolescentes do Gênero Feminino com Experiência de Viver na rua e em Abrigos. Tese de Doutorado não publicada, Universidade Federal de Goiânia, Goiânia.

Fávero, M., \& Santos, M. (2005). Autismo infantil e estresse familiar: uma revisão sistemática da literatura [versão eletrônica]. Psicologia: reflexão e crítica, 18 (3), pp. 358-369.

Ferreira, A. B. H. (2007). Miniaurélio: o minidicionário da língua portuguesa (6 ${ }^{\mathrm{a}}$. ed). Curitiba: Positivo.

Foucault, M. (1975). Doença Mental e Psicologia. Rio de Janeiro: Tempo Brasileiro.

Franco, V. (2016). Tornar-se pai/mãe de uma criança com transtornos graves do desenvolvimento [versão eletrônica]. Educar em Revista, (59), 3548.

Gadamer H. G. (1993). O mistério da saúde: o cuidado da saúde e a arte da medicina. Lisboa: Edições 70 .

Ginger, S., \& Ginger, A. (1995). Gestalt: uma terapia do contato. São Paulo: Summus.
Giorgi, A. (1985). Sketch of psychological phenomenological method. Em W. F. Fisher, A. Giorgi \& F. J. Wertz (Orgs.), Phenomenology and Psychological Research (pp. 8-22). Pittsburg: Duquesne University Press.

Holanda, A. F. (2014). Fenomenologia e Humanismo - Reflexões Necessárias. Curitiba: Juruá Editora.

Karwowski, S. L. (2015). Por um entendimento do que se chama psicopatologia fenomenológica. Revista da Abordagem Gestáltica, 21(1), 62-73. Recuperado em 06 de dezembro de 2018, de http://pepsic.bvsalud.org/scielo.php?script $=$ sci_arttext\&pi$\mathrm{d}=$ S1809-68672015000100007\&lng $=\mathrm{pt} \& \operatorname{lng}=\mathrm{pt}$

Kobasa, S. C., Hilkler, R., \& Maddi, S. R. (1979). Who stays healthy under stress? Journal of Occupational Medicine, 21, 595-598.

Laplanche, J. \& Pontalis, J. B. (1992). Psicose. Em Vocabulário da psicanálise (P. Tamen, trad.). São Paulo: Martins Fontes. (Trabalho original publicado em 1967).

Moreira, V. (2011). A contribuição de Jaspers, Binswanger, Boss e Tatossian para a psicopatologia fenomenológica. Revista da Abordagem Gestáltica, 17(2), 172-184. Recuperado em 04 de outubro de 2019, de http://pepsic. bvsalud.org/scielo.php?script =sci_arttext\&pi$\mathrm{d}=$ S1809-68672011000200008\&lng $=-$ pt\&tlng $=$ pt.

Minayo, M.C.S., Hartz, Z. A., \& Buss, P. M (2000). Qualidade de vida e saúde: um debate necessário. Ciência \& Saúde Coletiva, 5(1), 7-18.

Minkowski, E. (1973). El tempo vivido: estudios fenomenológicos y psicológicos. México D.F.: Fondo de Cultura Económica. (Trabalho Original Publicado em 1933).

Petrelli, R. (2008). Fenomenologia: teoria, método e prática. Goiânia: UCG.

Petrelli, R. (2017). Parecer do trabalho "Qualidade de Vida de Mães de Crianças com Transtorno do Espectro Autista - Uma Leitura Baseada no Método Fenomenológico" - Exame de Qualificação. Goiânia: Pontifícia Universidade Católica de Goiás.

Rehfeld, A. (2000). A prática clínica fenomenológico existencial. Revista de Gestalt, 9, 59-62.

Ribeiro, J. P. (1985). Gestalt-Terapia: Refazendo um Caminho. São Paulo: Summus.

Rovaletti, M. L. (2015). Alcance y Significación de la Psico(pato)logía Fenomenológica [versão eletrônica]. Revista da Abordagem Gestáltica, 21(2), 117-123. 
Sartre, J. P. (2012). O Ser e o Nada: Ensaio de Ontologia Fenomenológica. Petrópolis: Vozes.

Sivberg, B. (2002). Family system and coping behaviours: a comparison between parents of children with autistic spectrum disorders and parents with non-autistic children. Autism 6(4), 397-409.

Smith, J. A, Flowers, P., \& Larkin, M. (2009). Interpretative Phenomenological Analysis. Theory, Method and Reserche. Thousand Oaks: Sage Publications, 2009.

Stoner, J. B., \& Stoner, C. L. (2016). Career Disruption: The Impact of Transitioning From a Full-Time Career Professional to the Primary Caregiver of a Child With Autism Spectrum Disorder. Focus on Autism ond Other Developmental Disabilities, 31,2 (pp. 104-114).

Tinoco, D. H. (2012). Psicologia: uma ciência humana. Em: A. S. S. Berger, D. H. Tinoco, \& M. A. Chahine (Orgs.), A psicologia e o novo paradigma da ciência (pp.133-144). Londrina: Edunifil.

Yeargin-Allsopp, M., Rice, C., Karapurkar, T., \& Doemberg, N.; Boyle, C.; Murphy, C. (2003). Prevalence of autism in a US metropolitan area. Jama, 289, pp: 35-49.

Yontef, G. M. (1998). Processo, diálogo e awareness: ensaio em Gestalt-terapia. São Paulo: Summus.
Maria Paula Miranda Chaim (https://orcid. org/0000-0001-8872-7172) é Psicóloga; Mestre em Psicologia pela PUC-GO. Endereço Institucional: Rua 9 A; Q. H-1 Lt. 7/62, número 164, apto 1104, Residencial Constellation Life Style - Setor Oeste; CEP 74.110-110 Goiânia-GO. mpchaim@gmail.com

Sebastião Benicio da Costa Neto (http://orcid. org/0000-0001-8160-3476) é Professor Adjunto II, orientador de mestrado e doutorado no Programa de Pós-Graduação em Psicologia, da Pontifícia Universidade Católica de Goiás (PUC Goiás).

Aminny Farias Pereira (https://orcid.org/00000002-9761-1582) é Graduada em Psicologia pela Pontifícia Universidade Católica de Goiás (PUC GO).

Virgínia Elizabeth Suassuna Martins Costa (https://orcid.org/0000-0002-3348-9442) é Doutora em Ciências da Saúde pela UnB/UFG, Mestre em Educação pela PUC-GO e Psicóloga formada na Universidade de São Paulo - USP.

Recebido em 14.08.2018 Primeira Decisão Editorial 05.12.2018 Aceito em 24.04.2019 